\title{
The Satisfaction and Needs of Teachers on the Earth Science Model Experiments in Science Textbooks Used in Primary Schools
}

\author{
Ilho Yang ${ }^{1}$, Sungman $\operatorname{Lim}^{1 *}$ \\ ${ }^{1}$ Korea National University of Education, SOUTH KOREA \\ Received 9 February 2021 - Accepted 12 March 2021
}

\begin{abstract}
This study aimed to examine teachers' satisfaction with and needs for earth science model experiments science textbooks used in primary schools. To this end, 103 primary school teachers participated in an online survey, and five teachers with doctorates in science education theory were interviewed. The findings of the study were as follows. First, primary school teachers in South Korea were highly satisfied with earth science model experiments presented in science textbooks. Second, despite the high satisfaction, there were various reasons why model experiments were inappropriate and difficult to conduct. Third, the teachers wanted to replace the model experiments of earth science that could result in misconceptions, had low success rates, and were time-consuming to prepare. Fourth, when designing earth science model experiments, teachers felt the need to confirm the meaning and accessibility of the model experiments. This study confirmed that model experiments should have a meaning and emulate the facts to help students understand rather than merely imitate.
\end{abstract}

Keywords: science textbook, earth science, science model experiment, primary school teacher

\section{INTRODUCTION}

The curriculum is a big framework that shapes national education. The basic materials used to guide teaching and exploratory activities specified in the curriculum are science textbooks (Chiapetta \& Fillman, 2007; Hubisz, 2003; Leite, 1999; Liu \& Khine, 2016; Stoffels, 2005). Despite many materials and textbooks for scientific learning, teachers have traditionally relied on science textbooks (Roseman et al., 2001). Therefore, science textbooks play a significant role in science education (Lim, 2019).

Textbooks include the main activities designed to achieve such concepts as well as learning concepts defined in the curriculum. For example, Korean science textbooks consist of "achievement standards" stating the scientific concepts that students should acquire and "exploration activities" to assist the acquisition of concepts. As exploration activities in science textbooks are also a means of comprehending scientific concepts, it can be said that science textbooks have organized "science concepts" into specific activities.
The exploration activities presented in science textbooks are among the most important areas of science education. Through exploration activities, students have the opportunity to understand the processes and methods of the construction of scientific knowledge, solve problems around them in scientific ways, and develop their scientific skills (Chinn \& Malhotra, 2002; Hofstein, 2004; Wickman, 2004). In this regard, the question of "how to design specific exploration activities" related to the learning topics and concepts in textbooks is very important (Lim, 2020).

When exploration activities are designed, the activities should be directly related to the scientific concepts students aim to learn and should be designed to make the learning process easier for students. To design for this purpose, one must first identify the properties of exploration activities according to scientific concepts (Lim, 2020). Merely imitating and experiencing science itself does not guarantee scientific understanding (Sadler et al., 2010; Schwartz et al., 2004). In other words, merely imitating and experiencing phenomena related to scientific concepts does not help students understand scientific concepts. In particular, the field of earth science

(c) 2021 by the authors; licensee Modestum. This article is an open access article distributed under the terms and conditions of the Creative Commons Attribution License (http://creativecommons.org/licenses/by/4.0/). 


\section{Contribution to the literature}

- Primary school teachers in South Korea were highly satisfied with earth science model experiments presented in science textbooks. Despite the high satisfaction, there were various reasons why model experiments were inappropriate and difficult to conduct.

- When designing earth science model experiments, teachers need to confirm the meaning and accessibility of the model experiments.

- Merely imitating and experiencing science does not guarantee an understanding of science.

deals with concepts that are not only abstract but also represent large differences in time, distance, and size, thus making it difficult for students to directly observe such concepts (Duschl \& Smith, 2001; Kim et al., 1996; Kusnick, 2002; Lim \& Jeong, 1993; Wier et al., 2000). Various model experiments have been used in science textbooks to understand the concepts within earth science. However, if these model experiments stop at a level that mimics scientific phenomena, as discussed previously, or there is an error in such imitation, they can create another obstacle to learning as they may instill misconceptions among students. From this perspective, it is necessary to analyze experimental activities that model scientific phenomena designed in science textbooks.

Meanwhile, as Lederman et al. (2002), and Ucar (2012) pointed out, teachers' understanding of science has a significant impact on students' understanding of science. Most primary school teachers are not as effective in teaching science as in teaching other subjects (Kim, 2010), which means that they experience difficulties understanding science. In this regard, science textbooks need to be designed to be easy for teachers to understand and teach. In particular, if the exploration activities presented in science textbooks are not complicated or yield expected results, teachers will experience more difficulties in teaching science. Liu et al. (2012) reported that the self-efficacy and expectations of specific outcomes in science have a more significant influence on science professors' capacity than their teaching experience in the field of science. To enhance teachers' sense of self-efficacy in science, it is necessary to investigate and analyze what teachers think of science textbooks. From this perspective, this study is guided by the following questions based on what has been discussed above:

\section{Purpose of the Study}

- How satisfied are primary school teachers with the model experiments presented in science textbooks?

- Why do primary school teachers think that the model experiments presented in science textbooks are inappropriate?

- What kind of experimental activities do primary school teachers want in science textbooks?
- What form should earth science model experiments take?

\section{Earth Science, Exploration Activities, and Model Experiments}

The scientific phenomena dealt with in earth science usually involve substantial discrepancies in time, distance, and size. For example, the geology-related areas of earth science deal with the earth's history - that is, a timeframe of about 4.5 billion years. The research objects include the layers of soil accumulated during this period, ancient organisms, and changes in the atmosphere. For this reason, most scientific phenomena in the field of earth science include a variety of natural phenomena that are difficult to experience directly and are not possible to be recreated through controlled experiments (Gobert \& Clement, 1999).

Due to large discrepancies in time, distance, and size, the concepts covered in earth science are abstract and difficult to observe directly. In addition, repeated experiments are not possible (Lim \& Jeong, 1993). This makes it difficult for students to understand their educational content; earth science most likely instills wrong concepts in students more than in other scientific areas (Myeong, 2001).

On the other hand, Piaget's theory states that most primary school students are at the concrete operational stage, which means that they can enhance their learning experience and develop awareness through hands-on activities. In this regard, science has developed and organized various exploration activities related to scientific concepts, allowing students to understand them through operational activities. In other words, exploration activities allow learners to understand the processes and methods of constructing knowledge, solve problems around us in scientific ways, and develop scientific skills (Chinn \& Malhotra, 2002; Hofstein, 2004; Wickman, 2004). In particular, scientific exploration activities based on constructivist learning theory, a recent trend in education, including science education, can come in many forms but generally require students to learn concepts through practical experiences such as experiments (Suarez, 2011). Therefore, scientific exploration activities are essential.

The field of earth science also designs exploration activities with specific operational activities to understand the concepts. However, as previously noted, 
many exploration activities consist of model experiments because scientific phenomena addressed in earth science are often difficult to implement via realworld processes (Gorbert, 2000). For example, experiments related to a sedimentary rock formation, the process of fossil formation, and the rotation and revolution of the earth are all model experiments. In response, this study investigates if such model experiments could help students understand scientific phenomena and find areas for improvement.

The use of models to describe phenomena or processes that are difficult for students to experience in person increases their interest in their approach toward scientific concepts and is also useful in understanding such concepts (Grosslight et al., 1991; Kim \& Kim, 2009). Recently, interest in models in the field of science education has surged, with models representing various scientific phenomena being used as essential teachinglearning tools in scientific education (Gilbert et al., 2000). In this regard, teachers need to have the ability to design classes that can actively engage students in modeling (Acher et al., 2007; Akerson et al., 2009; Stylianidou et al., 2005). Explaining or designing models of scientific phenomena occurring in nature through model experiments is "authentic practice" (Hodson, 1998; Justi \& Gilbert, 2002).

On the other hand, recent science education has emphasized models and modeling concerning science process skills, but the US science education standards have emphasized the need to practice forming their own models or theories along with other scientific capabilities (National Research Council, 1996). Students can gain a more comprehensive understanding of phenomena, experiences, and theories through using models. In addition, modeling provides students the opportunity to test and understand their own mental models of natural phenomena through communication (Windschitl et al., 2008). Model experiment activity simplifies complex and large-scale natural phenomena and helps students understand natural phenomena through models. This process helps them form their own models of scientific phenomena to use for scientific reasoning.

\section{Science Textbooks in South Korea}

Textbooks are developed to ensure that teachers do not feel that the content and materials required to teach a given subject are lacking (Ball \& Feiman-Nemser, 1988; Yager, 1996), considering the school grade. In addition, as teachers use textbooks to help students reach the national curriculum goals (Rillero, 2010), textbooks, as well as accompanying materials, must meet the standards. In this regard, teachers are highly dependent on science textbooks (Schwarz et al., 2008). This is no exception in South Korea, where South Korea is more dependent on textbooks than other countries. Currently, primary school science textbooks in South Korea are controlled through a state-operated system that develops and distributes only one type of textbook according to the national curriculum. Compared to other countries where various kinds of textbooks are developed and teachers are offered a wide variety of choices, the importance the importance of, and proportion of topics in science textbooks in South Korea is higher. Exploration is one of the learning methods strongly supported in scientific teaching-learning for a very long time (Constantinou et al., 2018). For this reason, many countries emphasize exploration in science education, and related content is also included in science textbooks. Many countries, including the United States, Singapore, and Canada, organize and provide students with workbook-type textbooks with content related to exploration activities.

However, unlike other countries, although South Korea has a workbook, it was designed to be used only to note down the results of the exploration activities as the main content is presented in the textbooks. However, it can be said that South Korea places greater emphasis on exploration than other countries; for example, South Korean science textbooks note that one exploration activity is necessary per hour. Usually, in South Korean primary schools, science textbooks are composed of four units per semester, with one unit consisting of 12 hours. Therefore, approximately 10 exploration activities are organized per unit (Minister of Education, 2018). At the beginning of each school year, separate units were introduced and require scientific process skills before learning science-related content sections. Such composition is an example of the explicit emphasis on scientific exploration in science education and emphasizes the need for scientific process skills to understand scientific phenomena and acquire scientific concepts. Identifying the appropriateness and difficulty of experimental model activities in earth science in the Korean science textbook system, which emphasizes exploration activities, is a crucial part of successful scientific education.

\section{METHODS}

\section{Research Design and Process}

The study was conducted in accordance with the research procedures in Figure 1 to investigate teachers' satisfaction with and needs for earth science model experiments presented in science textbooks.

\section{Participants}

The study collected data through a survey using primary school teachers' model experiments and interviews with primary school teachers who hold doctoral degrees in the science education field. First, 103 primary school teachers were randomly sampled for the survey. Since the study used a survey program provided by an Internet portal site, the survey-related Internet 

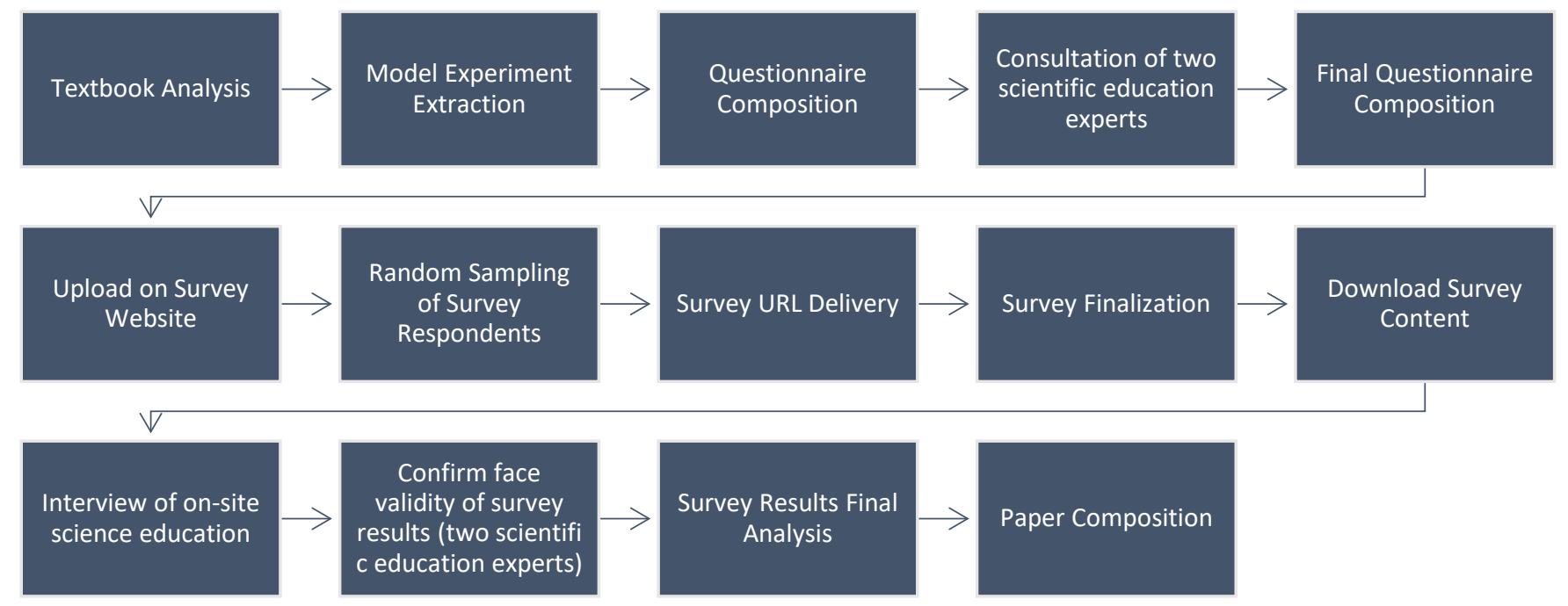

Figure 1. Research procedure

URL address (http:/ / naver.me/x9QmTxSp) was sent to 10 teachers across the country and via snowball sampling, those teachers sent it to nearby teachers. The 103 teachers randomly sampled consisted of 51 males $(49.5 \%)$ and 52 females $(50.5 \%)$ and broad teaching experiences. Second, five primary school teachers with doctorates in science education were selected for interviews with the fourth research question: "What form should earth science model experiments take?"

\section{Instrument and Data Collections}

The questionnaire developed for the study included 75 questions from 20 sections. Seven units dealt with earth science model experiments; there were a total of 18 experiments, as shown in Table 1. As shown in Figure 2, for each of the 18 model experiments, a five-point Likert scale questionnaire was constructed for teachers to evaluate the inappropriateness and difficulty. There was

Table 1. List of earth science model experiments

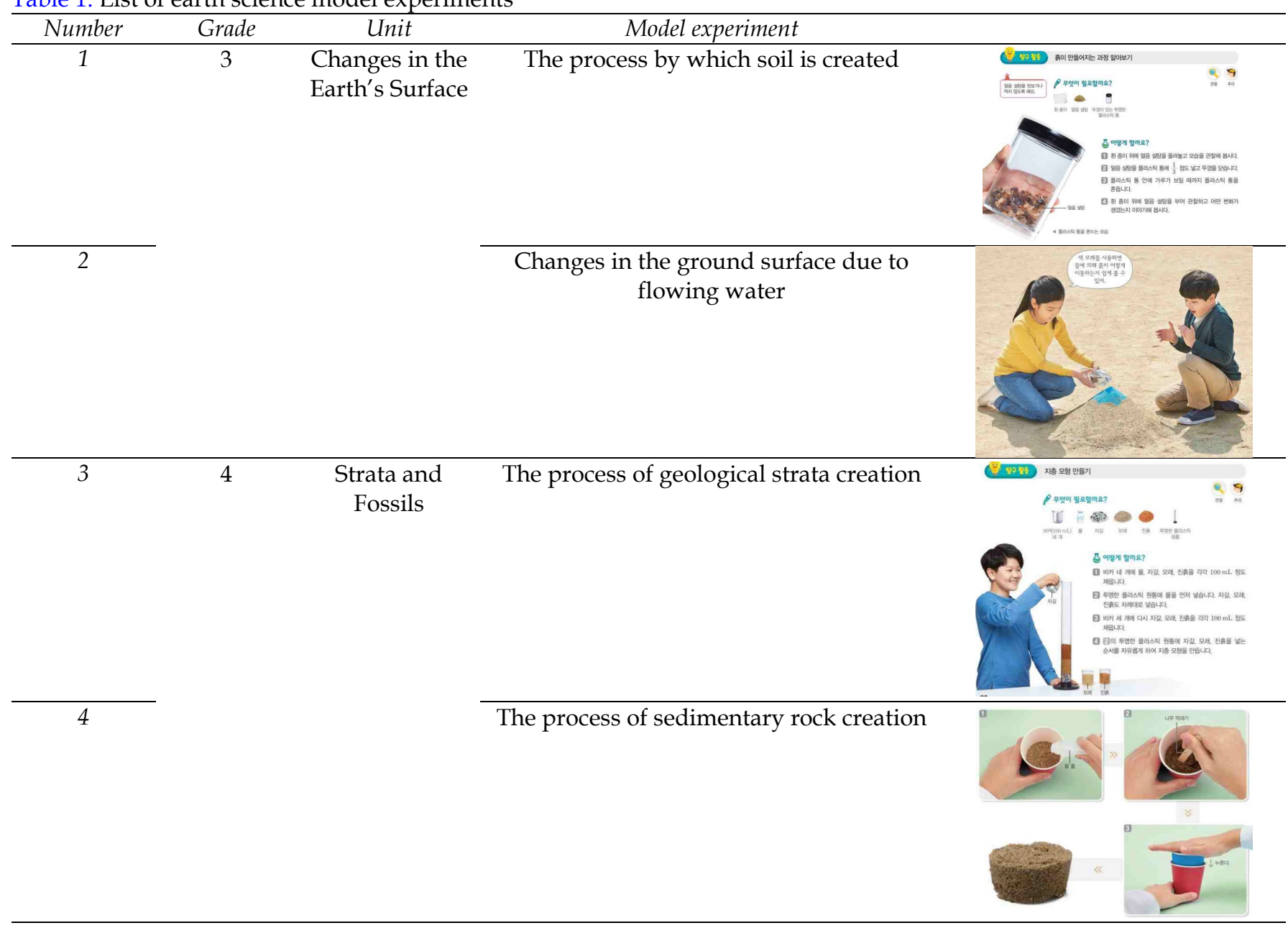


Table 1 (continued). List of earth science model experiments

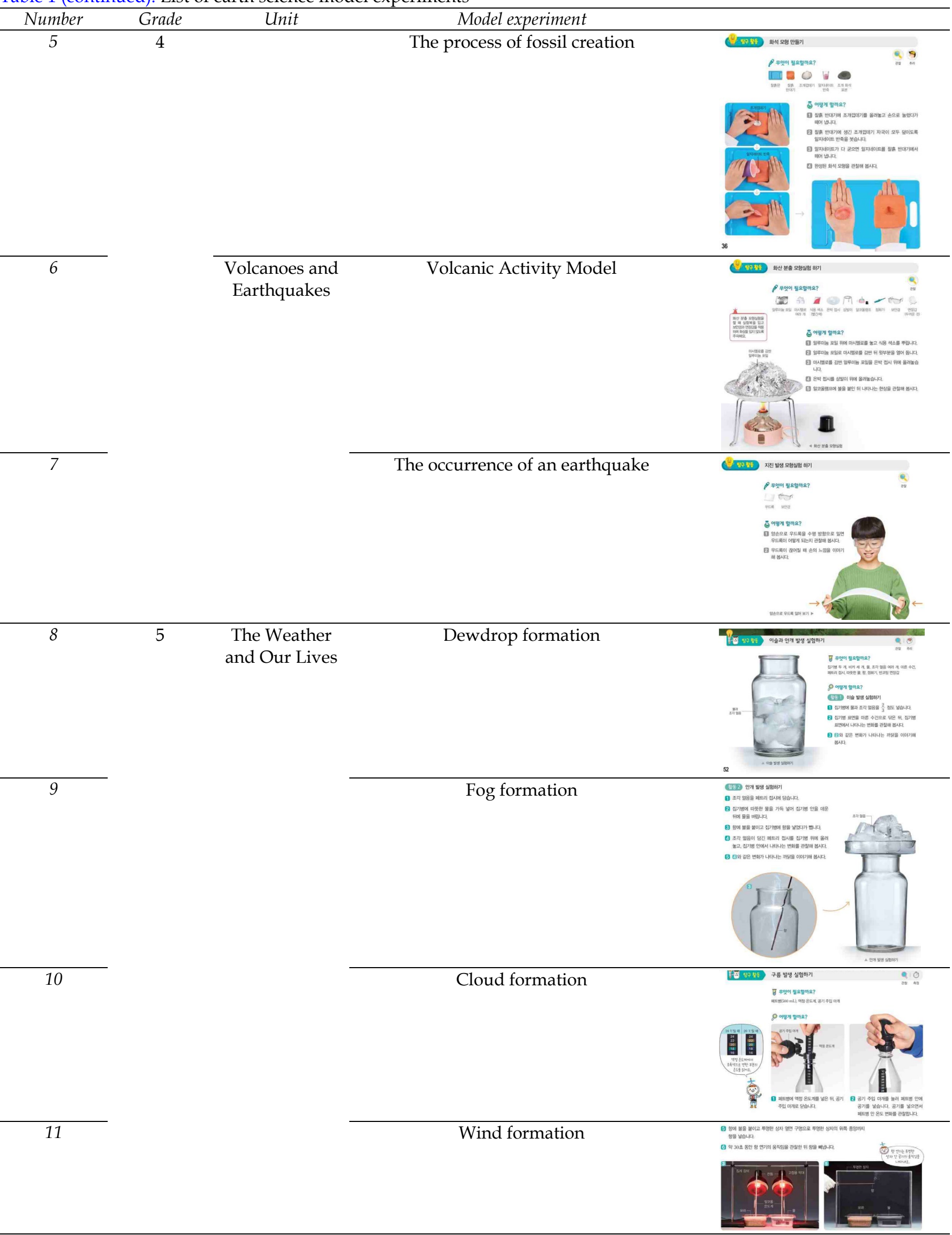


Table 1 (continued). List of earth science model experiments

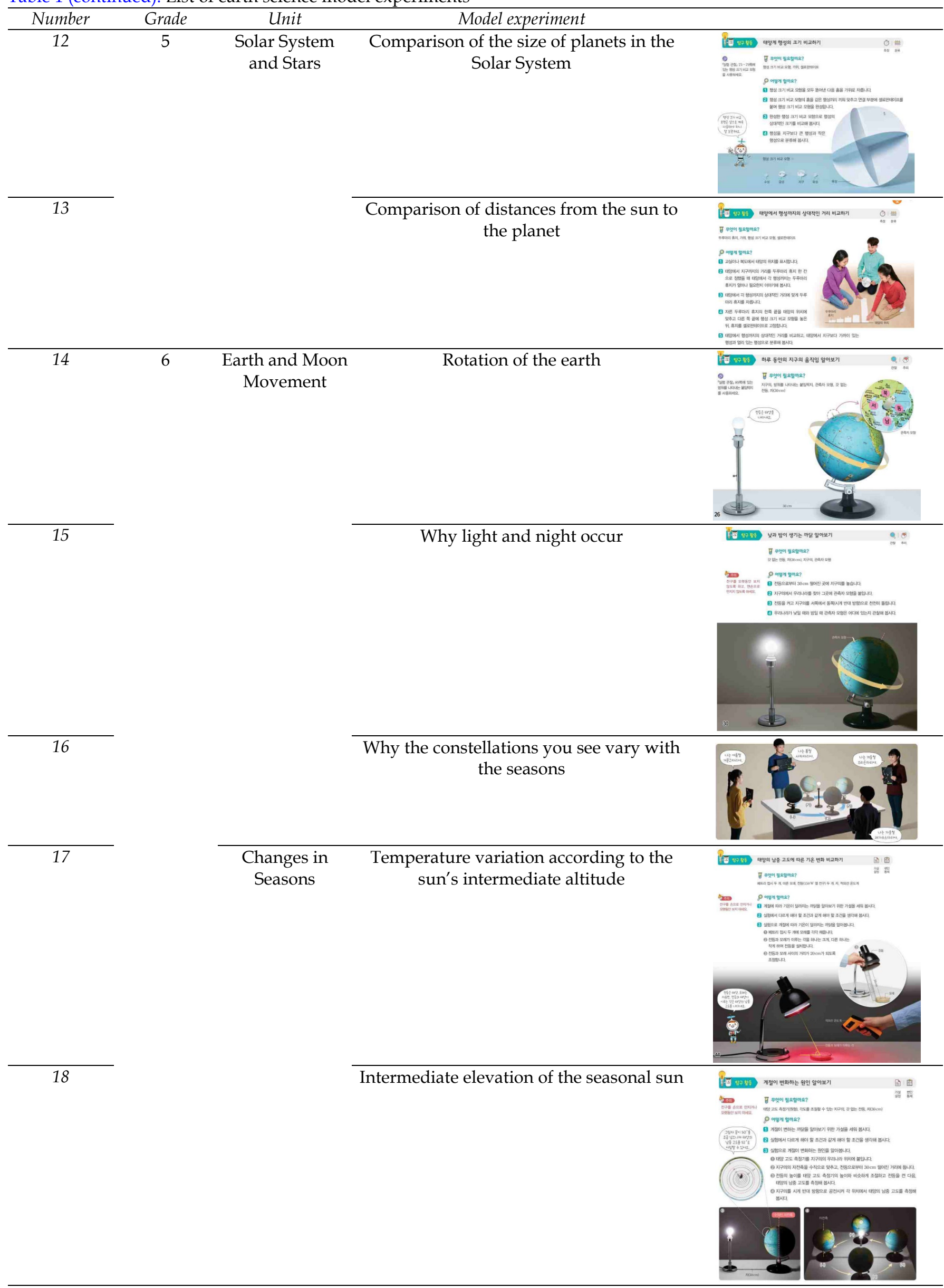




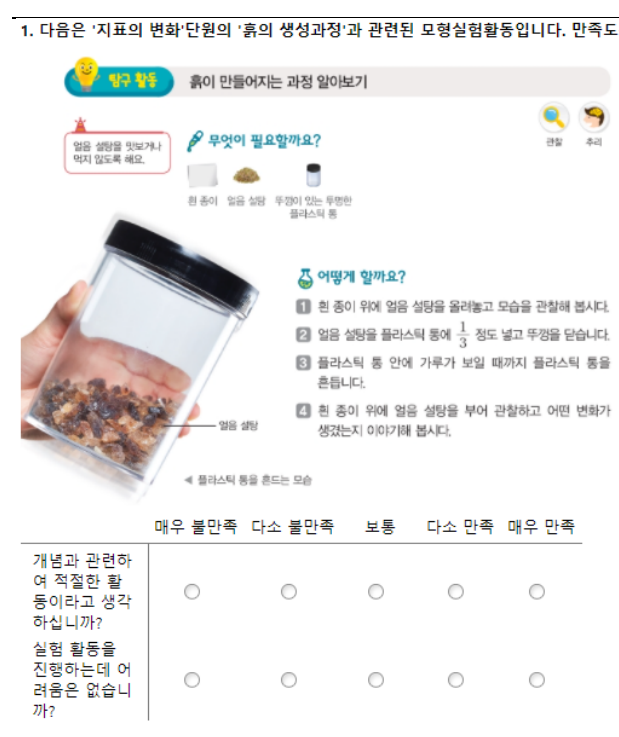

The following are experimental model activities related to the "The process in which soil is made" in the unit Changes in the Earth's Surface. Please check your level of satisfaction.

Exploration activity: finding out the process of how soil is made

* What do you need?

- White paper, icing sugar, a transparent plastic box with a lid

* What should we do?

1. Leave the icing sugar on the white paper and observe.

2. Put the icing sugar in the plastic box at the $1 / 3$ level and close the lid.

3. Shake the plastic box until you can see dust in the plastic box.

4. Pour the icing sugar on the white paper and talk about what changes have occurred.

Icing sugar

Shaking the icing sugar

@Do you think this is an appropriate activity related to the concept? @ Were there any difficulties in conducting the experiment?

Very dissatisfied - somewhat dissatisfied - average - somewhat satisfied - very satisfied

Figure 2. Example of survey questions

also a subjective questionnaire for teachers to respond to the difficulties in conducting the model experiment. After the 18 questions on the model experiments, we added a question asking teachers to select model experiments that needed to be replaced when developing new textbooks. The last question was a subjective question regarding the main points to consider when designing a new textbook.

After a face validity test with two science education experts, 75 questions were pilot-tested on five field teachers. We completed the final survey by modifying the feedback on the questionnaire's placement and readability identified through the face validity and pilot tests and uploaded it to the survey program. The survey program (http://naver.me/x9QmTxSp) was provided by the Korean portal site $\mathrm{N}$, and it was convenient to respond to and collect surveys from teachers across the country. The survey period was from December 1 to December 15, 2020 (15 days).

The second source of the study, interviews with an primary school teacher with a Ph.D. in science education theory were conducted from December 15 to December 22, 2020 (8 days). The interview was semi-structured, focusing on five key questions on the topic "What form should earth science model experiments take?" The main questions were focused on the satisfaction with the model experiments presented in the current textbook, the proportion of model experiments in earth science, the effectiveness of model experiments, the reasons teachers find them difficult, and points to consider when designing model experiments. Interviews with the study participants lasted an average of $40 \mathrm{~min}$.

\section{Data Analysis}

First, the collected data were compiled through technical statistics on the Likert scale of appropriateness and difficulty determined by teachers for each model experiment per the questionnaire. Second, questions on selecting model experiments that needed to be replaced when developing new textbooks were summarized using technical statistics. Third, the subjective questionnaire on why the model experiment was not appropriate, the difficulties in conducting the model experiment, the requirements for textbook development, and the interview data with primary school teachers were categorized through inductive content analysis used in qualitative research (Colaizzi, 1978). In particular, after all the interview data were transcribed, the transcribed data were read several times to select topics that were meaningful for this study, and the selected topics were read repeatedly to find topics and then categorized and organized (Huberman \& Miles, 1994).

\section{RESULTS}

\section{Question 1. Appropriateness of the Model Experiments of Earth Science and Satisfaction Regarding the Difficulty of Conducting the Experiment}

Primary school teachers were generally content with the appropriateness of earth science model experiments presented in science textbooks. Figure 3 shows that the mean for appropriateness is 4.12 , which is more than 4 , corresponding to the "satisfied" response. The model experiment that showed the highest level of satisfaction 


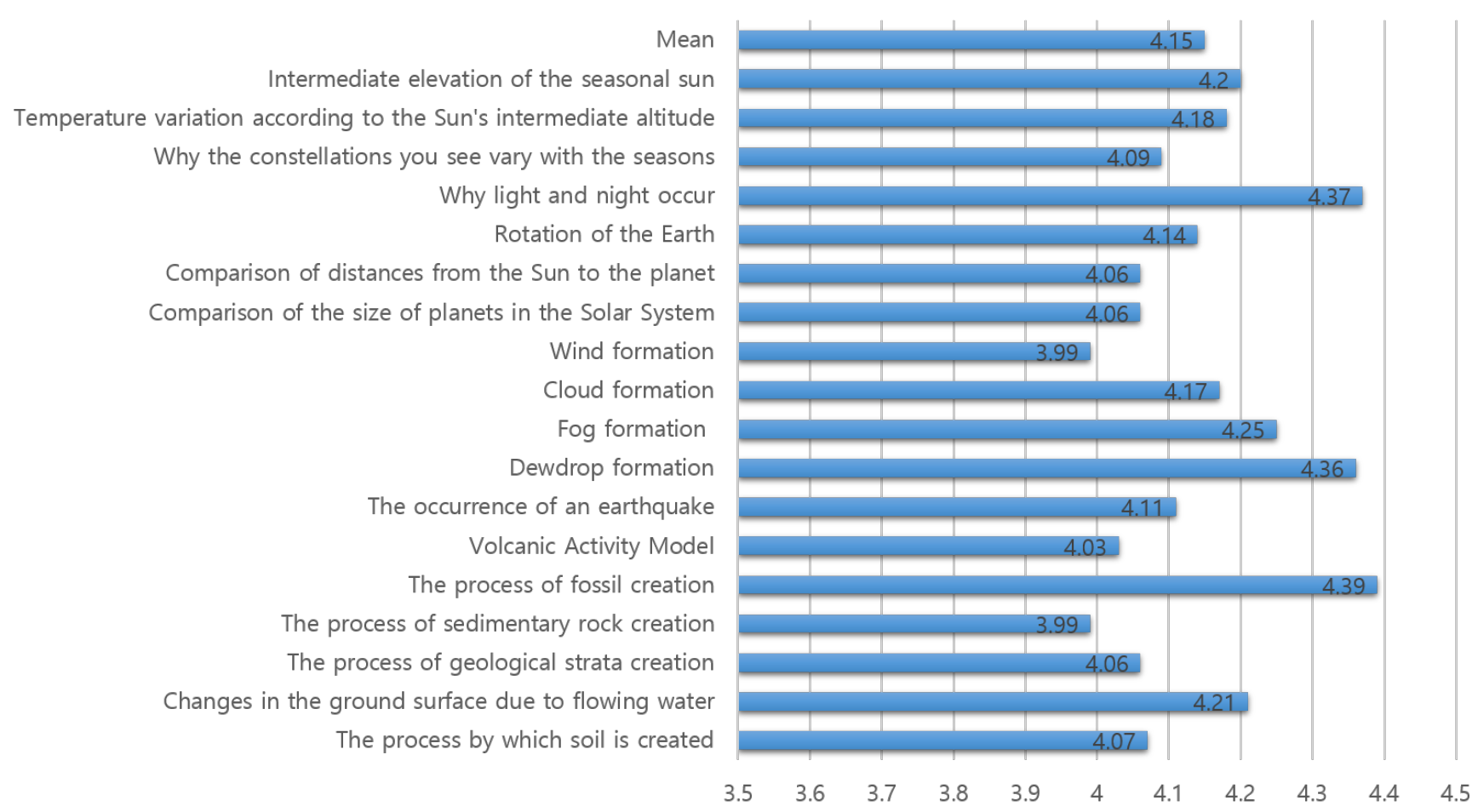

Figure 3. Appropriateness of the model experiment

Intermediate elevation of the seasonal sun Temperature variation according to the Sun's intermediate altitude Why the constellations you see vary with the seasons Why light and night occur Rotation of the Earth Comparison of distances from the Sun to the planet Comparison of the size of planets in the Solar System Wind formation Cloud formation Fog formation Dewdrop formation The occurrence of an earthquake Volcanic Activity Model

The process of fossil creation The process of sedimentary rock creation

The process of geological strata creation Changes in the ground surface due to flowing water The process by which soil is created

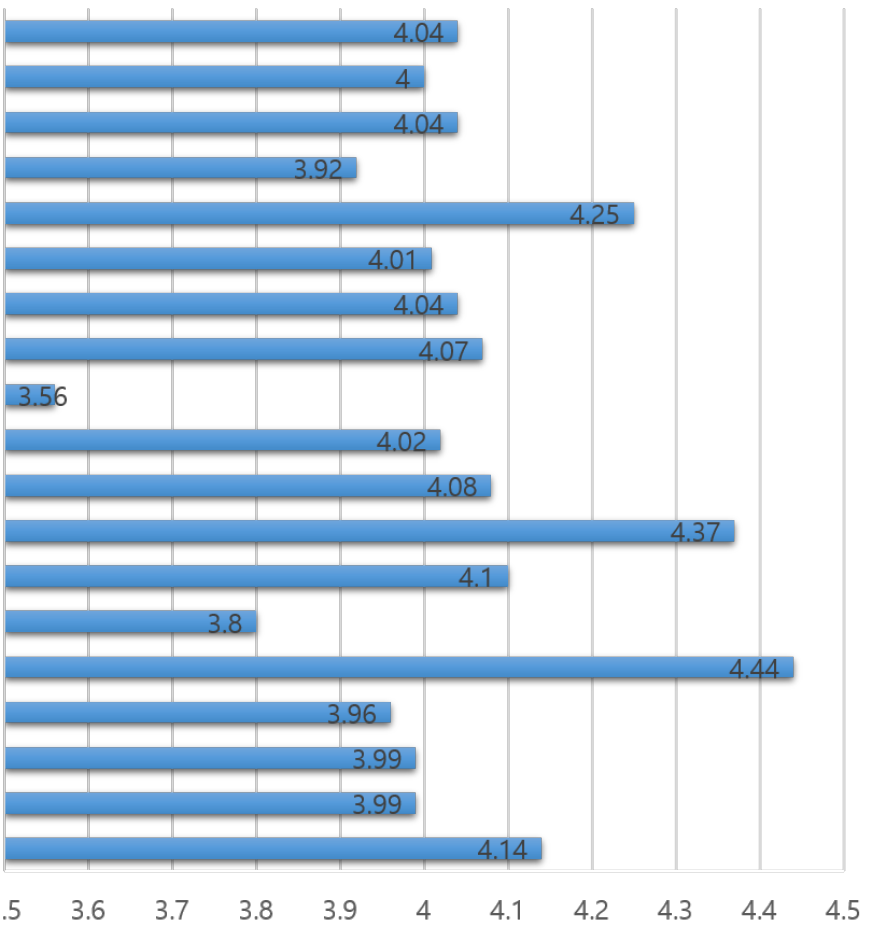

Figure 4. Difficulties of the model experiment

was on the process of making fossils (4.39 points); the model with the lowest level of satisfaction was "wind generation" (3.99 points). As mentioned previously, Korean primary school textbooks are designed for students to understand scientific concepts through simple hourly exploration activities. Therefore, the significance of exploration activities, that is, of model experiments, is very high (Gorbert, 2000). Teachers' high level of satisfaction with model experiments is good evidence that model experiments are effective in scientific education.

The survey results on the level of satisfaction with difficulties in conducting the model experiments are shown in Figure 4. Teachers generally do not find it difficult to conduct experiments. The average level of satisfaction with the experiment was 4.04 on average, indicating that participants were "satisfied." In particular, earth science model experiments describe 
Table 2. Why the model experiments are inappropriate

\begin{tabular}{ll}
\hline Category & Topic \\
\hline $\begin{array}{l}\text { Different from the } \\
\text { guidelines given in the }\end{array}$ & $\begin{array}{l}\text { (Sedimentary rock creation) The concept of sedimentary rocks presented in the curriculum is not } \\
\text { accurately described. }\end{array}$
\end{tabular}

curriculum (Cloud formation) The principles used in experiments are beyond the content and level of the curriculum.

(Comparison of distances from the sun to the planet) The concept of "ratio" is taught in grades higher than the current grade, which causes problems in the linkage of curriculum and students' understanding.

Incompatible with (Occurrence of earthquakes) Students do not understand the experimental process and the students' cognitive level meaning of the experiment.

(Cloud formation) The principles used in experiments are beyond the content and level of the curriculum.

(Comparison of planets in the Solar System) It is not easy to recognize the comparison in size.

(Earth's rotation) Students experience difficulty understanding the concept of space.

Lack of connection to the (Formation process of soil) It does not accurately explain the process of the formation of soil. concept

(Formation process of fossils) When made with alginate, the model fossils can become soft, instilling misconceptions.

Different from real (Process of soil formation) It is hard to say that this is a real weathering phenomenon.

nature.

(Volcanic activity models) There is a limit to understanding the various substances that emerge when a volcano erupts.

(Comparison of planets in the Solar System) As the planets are not spheres, misconceptions can be instilled.

phenomena or processes that are difficult to directly experience (Grosslight et al., 1991; Kim \& Kim, 2009), leading to complex and abstract experiments. It is challenging to complete the experiment successfully unless the teachers fully understand the content because the model experiment process requires experience or knowledge related to earth science phenomena. However, as the results show, the fact that teachers do not experience difficulties in the experimental process is a very positive science education indicator.

\section{Question 2. Reasons Why Model Experiments are Inappropriate and Complicated According to Teachers}

\section{Students like to experiment with models (Dr. Han).}

There is a limit to which the concept can be explained using only the actual phenomenon due to the nature of earth science. Model experiments play an essential role in eliciting children's understanding (Dr. Lim.)

The above is a discussion on model experiments by on-site teachers (hereinafter referred to as "on-site education experts") who have doctorates in science education theory. The importance of model experiments in science classes can be summarized as follows: Model experiments are essential in science classes as they are a way to elicit students' interest and teach difficult and abstract concepts. However, unlike most responses that reflected high satisfaction levels, there were also responses on why the model experiment was not appropriate. We comprehensively analyzed the reasons for each of the 18 model experiments' inappropriateness and inductively organized them (Table 2).

The responses as to why the model experiments were inappropriate were summarized into four categories. First, teachers responded that the model experiment's content was not appropriate, as it was different from the guidelines presented in the curriculum. In particular, there were many responses to the "cloud formation" experiment, and many teachers said that there were no guidelines for the curriculum to deal with the principles of cloud formation, claiming that it was not necessary to organize the experiment. Second, the teachers responded that the model experiment was not appropriate because it did not meet the students' cognitive level. Many related responses were received in a unit related to the field of "astronomy." Participants responded that primary school students did not understand the experiment's process or results because it was difficult to understand the abstract concept of "space" at the cognitive level. Third, teachers responded that model experiments that lacked an association with concepts were not appropriate. For example, model experiments on the process of soil formation, such as weathering, are different from actual natural phenomena and are not appropriate because they do not accurately explain the process of soil formation. Fourth, they responded that the model experiments in textbooks were not appropriate because they differed from actual natural phenomena. They responded that model experiments did not encompass scientific concepts as they only imitated the external factors of the phenomena 
Table 3. Why model experiments are difficult to conduct

\begin{tabular}{|c|c|}
\hline Category & Topic \\
\hline \multicolumn{2}{|c|}{$\begin{array}{l}\text { Teachers have difficulty in (Intermediate elevation of the seasonal sun) Even teachers find it difficult to understand the } \\
\text { understanding the procedure. }\end{array}$} \\
\hline \multirow[t]{2}{*}{ experiment } & (Earth's rotation) Even teachers find it difficult to understand the experiment. \\
\hline & (Fog formation) Teachers find it hard to explain the role of the smoke. \\
\hline \multirow{3}{*}{$\begin{array}{l}\text { Execution of the } \\
\text { experiment did not go } \\
\text { smoothly }\end{array}$} & $\begin{array}{l}\text { (Changes in the ground surface due to flowing water) It is difficult to obtain good experimental } \\
\text { results as there are many experimental variables. }\end{array}$ \\
\hline & (Wind formation) The experiment does not work well. \\
\hline & $\begin{array}{l}\text { (Why the constellations you see vary with the seasons / Intermediate elevation of the seasonal } \\
\text { sun) There is a high possibility of errors when moving the globe. } \\
\text { (Cloud formation) Students find it difficult to operate laboratory instruments. }\end{array}$ \\
\hline \multirow[t]{2}{*}{$\begin{array}{l}\text { Difficulty to obtain } \\
\text { definite results }\end{array}$} & $\begin{array}{l}\text { (Formation process of sedimentary rocks) It takes too long (more than one day) to produce } \\
\text { results. }\end{array}$ \\
\hline & (Cloud formation) It is difficult to identify a significant temperature change. \\
\hline \multirow{2}{*}{$\begin{array}{l}\text { Difficulty to find } \\
\text { materials for the } \\
\text { experiment }\end{array}$} & (Formation process of soil) It is not easy to find icing sugar. \\
\hline & $\begin{array}{l}\text { (Changes in the ground surface due to flowing water) It is challenging to conduct the } \\
\text { experiment at a school without a field. }\end{array}$ \\
\hline Unsafe experiment & $\begin{array}{l}\text { (Volcanic activity model) The experiment is dangerous because of the use of fire and the } \\
\text { emission of hot substances. }\end{array}$ \\
\hline
\end{tabular}

that occur in real nature. In this regard, the on-site education expert Dr. Han said the same thing.

I think that an inappropriate experiment can cause misconceptions (Dr. Han).

The responses regarding the difficulty of teachers conducting model experiments were categorized into five groups: "Because it was difficult for teachers to understand the experiment," "Because the experiment was not smoothly conducted," "Because it was difficult to obtain definite results," "Because it was difficult to find materials for the experiment," and "Because the experiment was not safe" (Table 3). Five field education experts agreed on this aspect. As shown in the interview below, we found that the model experiments were difficult to conduct because they could not yield definite results that could explain the actual natural phenomena in relation to their meaning and be reproduced and because teachers did not fully comprehend the concept.

In earth science model experiments, many large-scale experiments require much preparation or must be conducted by a class representative (teacher). On the other hand, there have often been cases where no visible results that students can easily understand could be obtained from the experiment. We also had many instances in which the experiment results were not apparent because of various variables (Dr. Lee).

Teachers lack awareness of model experiments in textbooks. Many researchers believe that all experiments will yield perfect results. They believe the experiment is easily reproducible. However, in the case of model experiments in earth science, reproducibility varies depending on the situation. [omitted] We need to interpret the results of the experiment flexibly. Furthermore, there are cases in which the concept is not correctly explained when there is a lack of subject-specific knowledge related to experiments. I also think that teachers have a hard time due to their lack of understanding of science (Dr. Lim).

\section{Question 3. Earth Science Model Experiments that Teachers Want}

Teachers showed a high level of satisfaction with the model experiments presented in the textbook, but they also suggested proper geoscience model experiments, presenting various difficulties. In response, we analyzed what type of earth science model experiments the teachers preferred. To this end, we asked which of the 18 model experiments in earth science needed to be replaced. The result was that teachers (excluding the 46 who did not respond) mostly wanted the Volcanic Explosion Model Experiment replaced (17 people, $16.5 \%)$. This is an experiment that shows the process of magma eruption rather than exploding. Learners can observe what happens when they put marshmallows and red pigments in silver foil, shape it into a volcano form, and heat it.

For this experiment, many teachers responded that many variables affect the experiment and that it is not an appropriate reproduction of real-world phenomena. They also reported that there are various safety issues in this experiment. Figure 5 gives teachers' responses to the model experiments they considered replacing. In addition, other experiments that teachers thought should be replaced were "wind formation," "formation of sedimentary rocks," and "the comparison of the size of planets in the Solar System."

The reasons why teachers wanted to replace certain model experiments were as follows: Some model experiments have low success rates, which can lead to misconceptions among students. Experiments such as 


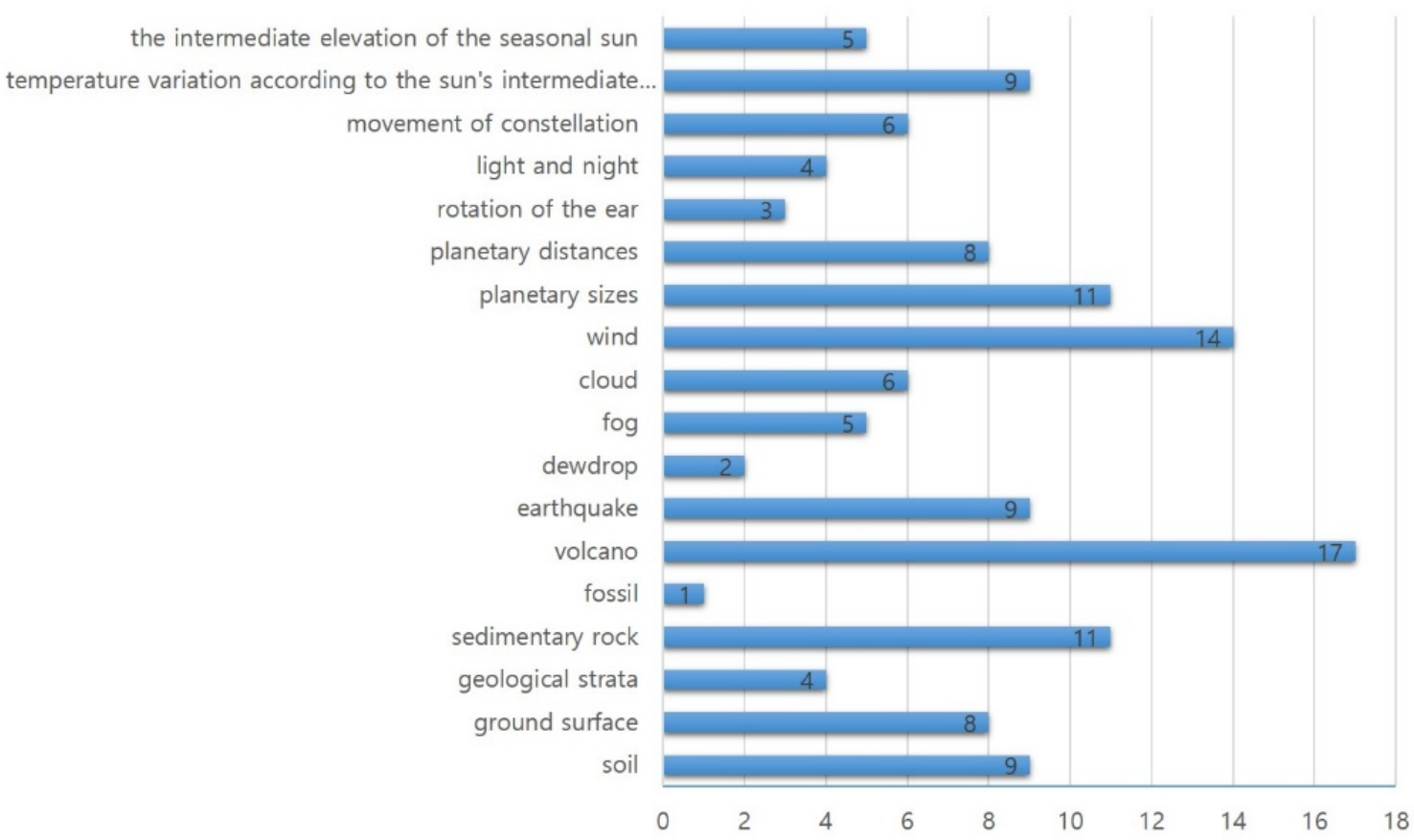

Figure 5. Model Experiments that need to be replaced

"Comparison of the size of planets in the Solar System," for example, can make it difficult for students to grasp the actual size of planets. To summarize:

Experiments can create misconceptions.

The success rate of some experiments is low.

The experiments differ significantly from real phenomena and do not enhance real understanding.

The conditions on-site are not in place.

There are safety issues.

The results are not clear.

They do not help us understand the concept.

Preparing the experiment is too time-consuming.

\section{Question 4. Things to Consider When Designing a Model Experiment in Earth Science}

Compared to other subjects, earth science involves many concepts that are difficult to observe directly because these concepts are not only abstract but associated with large discrepancies in time, distance, and size (Duschl \& Smith, 2001; Kim et al., 1996; Kusnick, 2002; Lim \& Jeong, 1993; Wier et al., 2000). For this reason, many model experiments have been organized in textbooks to enhance students' understanding. However, as we have seen in this study, despite the high level of satisfaction of on-site teachers, there were various questions regarding the appropriateness and difficulty of the experimental process. To improve these model experiment problems, we surveyed on-site teachers, interviewed on-site teachers with doctorates in science education, and summarized the results. Based on the analysis, we organized the following: Teachers responded that experiments should meet the required conditions for model experiments and satisfy field application requirements.

They should be similar to real phenomena.

Students should be able to understand intuitively.

The concept should be understood effectively.

Students' level of background knowledge and cognitive level should be considered.

There should be fewer errors.

It should be possible to conduct experiments on-site.

Experimental activities should be easy.

One must be able to obtain definite results from the experiment.

The preparation of experimental materials should not be expensive.

The experiment must be safe.

The above opinions could be summarized into two main categories. The first was to reconfirm the meaning of the model experiment. The second involved the accessibility of the model experiment. First, model experiments should be structured to suit the meaning and purpose of model experiments that $\mathrm{s}$ reproduce scientific phenomena, that is, natural phenomena. In response, on-site education expert Dr. Lim pointed out that it is more important to reproduce only the important parts than to regenerate the entire natural phenomenon and that the teacher's explanation should replace the remainder.

I think that it is more important to focus and model the most important part of the phenomenon aimed to reproduce rather than trying to recreate the entire natural phenomena. In other words, it would be desirable to recreate only a part of 
the phenomenon through selection and focus and to supplement the rest with theory or explanation (Dr. Lim).

In particular, earth science model experiments show large discrepancies in scale to natural phenomena, making it difficult to convey the actual phenomenon realistically. Therefore, the guidelines according to which the experiments should be designed are clear. In other words, only a small part of the natural phenomenon should be reproduced to help students understand the concept. Teachers should also note this, and they should explain the scientific concepts associated with this phenomenon. When this happens, many teachers will realize the demand that "model experiments should be structured to understand concepts effectively."

The second point of consideration when designing the model experiments was the ease of the experiments. As mentioned in Dr. Moon's interview: "It would be nice to organize an easy, fun, and intuitive experiment." A model experiment should be interesting, easy, and not difficult for students to understand. Additionally, it should not be difficult for teachers to explain. These include the need to reflect students' level of cognition and to achieve definite experimental results.

\section{DISCUSSION AND CONCLUSION}

Merely imitating and experiencing science does not guarantee an understanding of science (Sadler et al., 2010; Schwartz et al., 2004). In this regard, model experiments should not simply imitate natural phenomena but must strategically imitate them to help students understand them. In other words, as teachers demanded in the research results, natural phenomena should not be reproduced as they are but should be configured after identifying important parts and reflecting their characteristics. In doing so, the experiment will clearly distinguish between what students need to observe and what teachers need to explain with regard to model experiments and allow students to understand natural phenomena comprehensively. However, mere imitation makes it difficult for teachers to explain. Students will lose interest and experience difficulties in understanding due to complex experimental processes.

Compared to other countries, Korean primary school science textbooks emphasize exploration activities, and exploration activities account for most of the teaching (Lim, 2018). In these situations, exploration activities take up a very high proportion of the entire learning process. In addition, if exploration activities such as model experiments are not appropriate in understanding scientific concepts, students will experience difficulties in learning science. In this regard, exploration activities such as model experiments should consist of an easy experimental process that can lead to definite experimental results, as shown in this study. If the experimental process is complicated, and teachers do not fully understand the concept to help students, or if the experiment itself is not conducted properly, it may be difficult to satisfy the learning goals.

Most teachers were satisfied with the earth science model experiments presented in South Korea's primary school science textbooks. This is a very positive indicator, providing evidence that the model experiments presented in the textbook help students learn science. However, there were many problems despite the high levels of satisfaction. Therefore, it is very important to improve these aspects. In particular, as Lim (2015) pointed out, despite many revisions made to primary school science textbooks in South Korea over a long period of time, not many changes were made to the scientific concepts or exploration activities. In other words, the attitude toward developing new exploration activities has been very passive. There would be no problem if the present exploration activities were effective, but as many teachers pointed out in this study, there were various inappropriate aspects and difficulties in model experiments. This should be improved appropriately. Such efforts are also consistent with the direction in which recent science textbooks have designed and organized content focusing on exploration (Stoffels, 2005).

As noted repeatedly in this study and prior studies, experiments related to earth science are difficult to design compared to other areas due to the characteristics of the field of earth science. Because of the extent of the timeframes and space and the abstract concepts involved, students experience difficulty understanding phenomena related to earth science. Model experiments are essential to compensate for this. When designing earth science model experiments in the future, we should not overlook the meaning of model experiments noted in this study's results and the easy accessibility of experiments that can be conducted in science classes. As discussed previously, model experiments should not merely be imitations but must be meaningful imitations that enhance understanding. The purpose of the experiment, to enhance students' understanding, should be reconsidered.

Specifically, to simplify actual natural phenomena and organize them into experimental activities, the following conditions should be considered. First, the entire natural phenomena to be constructed is not modeled as an experimental activity but rather modeled by focusing on what students need to understand natural phenomena. Models should be understood as simplified representations of objects, realities, and phenomena to understand and explain scientific phenomena (Chamizo, 2013; Gobert \& Buckley, 2000; National Research Council, 2012). Second, a sequence of imitations of the model experiment was presented. In other words, it is necessary to specify what the model experiment activity imitates among natural phenomena 
such as time, shape, continuity, etc., and the sequence of the imitation. Third, the model activity is organized into a simple process so that students can understand it easily. That is, if the constructed model experiment is too complex or problematic, one cannot expect an effective learning outcome. Fourth, after the model experiment activity is completed, an activity to compare with actual natural phenomena is conducted. This is to help students understand that model experimentation is an inquiry activity to understand natural phenomena. In addition, through these activities, students can understand the scale of actual natural phenomena.

Author contributions: All authors have sufficiently contributed to the study, and agreed with the results and conclusions.

Funding: No funding source is reported for this study.

Declaration of interest: No conflict of interest is declared by authors.

\section{REFERENCES}

Acher, A., Arcà, M., \& Sanmartí, N. (2007). Modeling as a teaching learning process for understanding materials: A case study in primary education. Science Education, 91(3), 398-418. https:// doi.org/ 10.1002/sce. 20196

Akerson, V. L., Townsend, J. S., Donnelly, L. A., Hanson, D. L., Tira, P., \& White, O. (2009). Scientific modeling for inquiring teachers network (SMIT'N): The influence on primary teachers' views of nature of science, inquiry, and modeling. Journal of Science Teacher Education, 20(1), 21-40. https://doi.org/ 10.1007/s10972-008-9116-5

Ball, D. L., \& Feiman-Nemser, S. (1988). Using textbooks and teacher's guides: A dilemma for beginning teachers and teacher educators. Curriculum Inquiry, 18(4), 401-423. https:/ / doi.org/10.2307/1179386

Chamizo, J. A. (2013). A new definition of models and modeling in chemistry' teaching. Science and Education, 22(7), 1613-1632. https://doi.org/ $10.1007 /$ s11191-011-9407-7

Chiappetta, E., \& Fillman, D. (2007). Analysis of five high school biology textbooks used in the United States for inclusion of the nature of science. International Journal of Science Education, 29(15), 1847-1868. https: / / doi.org/10.1080/09500690601159407

Chinn, C. A., \& Malhotra, B. A., (2002). Epistemologically authentic inquiry in schools: A theoretical framework for evaluating inquiry tasks. Science Education, 86(2), 175-218. https:// doi.org/ 10.1002/sce.10001

Colaizzi, P. E. (1978). Psychological research as the phenomenologist view it existential phenomenology. Oxford University press.

Constantinou, C. P. Tsivitanidou, O. E., \& Rybska, E. (2018). What Is Inquiry-Based Science Teaching and Learning?. In O. E. Tsivitanidou, et al. (Eds.),
Professional development for inquiry-based science teaching and learning (pp. 1-23). Contributions from Science Education Research 5. https://doi.org/ 10.1007/978-3-319-91406-0_1

Duschl, R., \& Smith, M. (2001). Earth science. In J. Brophy (Ed.) Subject-specific instructional methods and activities (Advances in Research on Teaching, Vol. 8, pp. 269-290). Emerald Group Publishing Limited, Bingley. https://doi.org/10.1016/S1479-3687(01) 80030-4

Gilbert, J., Boulter, C., \& Rutherford, M., (1998). Models in Explanations, Part 1; Horses for Courses. International Journal of Science Education, 20(1), 8397. https:/ / doi.org/10.1080/0950069980200106

Gobert, J. D. (2000). A typology of causal models for plate tectonics: Inferential power and barriers to understanding. International Journal of Science Education, 22(9), 937-977. https:/ / doi.org/10.1080/ 095006900416857

Gobert, J. D., \& Buckley, B. C. (2000). Introduction to model-based teaching and learning in science education. International Journal of Science Education, 22(9), 891-894. https://doi.org/10.1080/ 095006900416839

Grosslight, L., Unger, C., Jay, E., \& Smith, C. L. (1991). Understanding models and their use in science: Conceptions of middle and high school students and experts. Journal of Research in Science Teaching, 28(9), 799-822. https://doi.org/10.1002/tea. 3660280907

Hodson, D. (1998). Teaching and learning science: Towards a personalized approach. McGraw-Hill Education.

Hofstein, A., \& Lunetta, V. N. (2004). The laboratory in science education: foundation for the 21st century. Science Education, 88(1), 28-54. https://doi.org/ 10.1002/sce.10106

Huberman, A. M., \& Miles, M. (1994). Qualitative Data Analysis. Sage Publications.

Hubisz, J. (2003). Middle-school texts don't make the grade. Physics Today, 56(5), 50-54. https:/ / doi.org/10.1063/1.1583534

Justi, R. S., \& Gilbert, J. K. (2002). Modelling, teachers' views on the nature of modelling, and implications for the education of modellers. International Journal of Science Education, 24(4), 369-387. https:// doi.org/10.1080/09500690110110142

Kim, B., Lee, H., \& Kim, G. (1996). A study on the relationships between achievement about astronomical concept and spatial ability. Journal of Korean Primary Science Education, 15(2), 315-325. http:/ / www.riss.kr/link?id=A3065260

Kim, H. (2010). An Analysis of Primary Science Teaching Efficacy. Journal of educational studies (in Korea), 41(1), 97-118. http://www.riss.kr/link?id= A82345176 
Kim, M., \& Kim, H. (2009). Analysis of the Types of Scientific Models in the Life Domain of Science Textbooks. Journal of the Korean Association for Science Education, 29(4), 423-436. http:/ / www.riss. $\mathrm{kr} /$ link?id=A76547748

Kusnick, J. (2002). Growing pebbles and conceptual prisms; Understanding the sources of student misconceptions about rock formation. Journal of Geoscience Education, 50(1), 31-39. https:/ / doi.org/ 10.5408/1089-9995-50.1.31

Lederman, N. G., Abd-El-khalick, F., Bell, R. L., \& Schwartz, R. S. (2002). Views of nature of science questionnaire: Toward valid and meaningful assessment of learners' conceptions of nature of science. Journal of Research in Science Teaching, 39(6), 497-521. https:/ / doi.org/10.1002/tea.10034

Leite, L. (1999). Heat and temperature: an analysis of how these concepts are dealt with in textbooks. European Journal of Teacher Education, 22(1), 75-88. https:/ / doi.org/10.1080/0261976990220106

Lim, C., \& Jeong, J. (1993). An analysis of contents and problems on astronomical area in the primary science textbooks. Journal of the Korean Association for Research in Science Education, 13(2), 247-256. http:/ / www.riss.kr/link?id=A3255222

Lim, S. (2015). An Analysis of Concepts and Inquiry Activities related to the 'Earth Science' Area in the South Korean Primary School Textbooks to the Current \& A Study on the Improvement of Future Textbook. The Korean Society of Primary Science Education, 34(3), 288-296. https:/ / doi.org/10.15267 / keses.2015.34.3.288

Lim, S. (2018). A Comparative Study on Concepts and Inquiry Activities in Primary Science Textbooks between Korea and Singapore: Focus on the Field of Geology. Journal of Korean Society of Earth Science Education, 11(1), 38-54. https://doi.org/10.15523/ JKSESE.2017.10.1.38

Lim, S. (2019). Needs and Directions for Developing Localization Materials in Geology in Primary Science Textbooks; Focused on the Unit of 'Strata and Fossils'. Journal of Korean Society of Earth Science Education, 12(3), 184-197. http:/ / www.riss.kr/link? $\mathrm{id}=\mathrm{A} 106510568$

Lim, S. (2020). Analysis of Teaching Strategies, Types of Inquiry Activities and the Relationship between Inquiry Activities and Concepts Presented in Primary School Science Textbooks; Focusing on Earth Science. The Korean Society of Primary Science Education, 39(3), 449-463. http:/ / www.riss.kr/link? id $=$ A107017141

Liu, X., Liang, L., \& Liu, E. (2012). Science education research in China: challenges and promises. International Journal of Science Education, 34(13),
1961-1970.

https:/ / doi.org/10.1080/09500693.2012.709330

Liu, Y., \& Khine, M. S. (2016). Content Analysis of The Diagrammatic Representations of Primary Science Textbooks. Eurasia Journal of Mathematics, Science and Technology Education, 12(8), 1937-1951. https:/ / doi.org/10.12973/eurasia.2016.1288a

Minister of Education, (2018). Primary science teachers' guide book-3rd grade. Visang Corporation.

Myeong, J. (2001). A study on the motions of the moon and the planets; Reasons for unsuccessful earth science problem solving of pre-service teachers. Journal of the Korean Earth Science Society, 22(5), 339349. http://db.koreascholar.com/article.aspx? code $=304213$

National Research Council (1996). National education standards. National Academy Press.

National Research Council. (2012). A framework for K-12 science education: practices, cross-cutting concepts, and core ideas. committee on a conceptual Framework for new K-12 science education standards. National Academy Press.

Rillero, P. (2010). The rise and fall of science education: A content analysis of Science in primary reading textbooks of the 19th century. School Science and Mathematics Journal, 110(5), 277-286. https://doi.org/10.1111/j.1949-8594.2010.00034.x

Roseman, J. E., Kulm, G., \& Shuttleworth, S. (2001). Putting textbooks to the test. ENC Focus, 8(3), 56-59.

Sadler, T. D., Burgin, S., Mckinney, L., \& Ponjuan, L. (2010). Learning Science through Research Apprenticeships: A Critical Review of the Literature. Journal of Research in Science Teaching, 47(3), 235-256. https:/ / doi.org/10.1002/tea.20326

Schwartz, R. S., Lederman, N. G., \& Crawford, B. A. (2004). Developing views of nature of science in an authentic context: An explicit approach to bridging the gap between nature of science and scientific inquiry. Science Education, 88(4), 610-645. https:/ / doi.org/10.1002/sce.10128

Schwarz, C. V., Gunckel, K. L., Smith, E. L., Covitt, B. A., Bae, M., Enfield, M., \& Tsurusaki, B. K. (2008). Helping primary preservice teachers learn to use curriculum materials for effective science teaching. Science Education, 92(2), 345-377. https://doi.org/ 10.1002 /sce. 20243

Stoffels, N. T. (2005). "There is a worksheet to be followed": A case study of a science teacher's use of learning support texts for practical work. African Journal of Research in Mathematics, Science and Technology Education, 9(2), 147-157. https:/ / doi.org/10.1080/10288457.2005.10740585

Stylianidou, F., Boohan, R., \& Ogborn, J. (2005). Science teachers' transformations of the use of computer modeling in the classroom: Using research to 
inform training. Science Education, 89(1), 56-70. https://doi.org/10.1002/sce.20043

Suarez, M. L. (2011). The Relationship Between InquiryBased Science Instruction and Student Achievement (Doctoral dissertation), University of Southern Mississippi.

Ucar, S. (2012). How do pre-service teachers' view on science, scientists, and science teaching change over time in a science teacher training program. Journal of Science Education and Technology, 21(2), 255-266. https:// doi.org/10.1007/s10956-011-9311-6

Wickman, P. O. (2004). The practical epistemologies of the classroom: a study of laboratory work. Science Education, 88(3), 325-344. https:// doi.org/10.1002/ sce.10129
Wier, B., Cain, B. J., \& Fredricks, K. (2000). “Living inside the earth", Children's preconceptions about how we addressed them. Paper presented at the national conference of the National Science Teachers Association, Orlando, FL.

Windschitl, M., Thompson, J., \& Braaten, M. (2008). Beyond the scientific method: Model-Based Inquiry as a new paradigm of preference for school science investigations. Science Education, 92(5), 941-967. https:// doi.org/10.1002/sce.20259

Yager, R. E. (1996). Science/Technology/Society as reform in science education. State University of New York Press.

\section{http://www.ejmste.com}

